\title{
HIV Self-Testing in Resource-Limited Settings: Regulatory and Policy Considerations
}

\author{
Vincent Wong • Cheryl Johnson · Elliot Cowan • \\ Matthew Rosenthal - Rosanna Peeling • \\ Maria Miralles · Anita Sands · Charlene Brown
}

Published online: 24 June 2014

(C) Springer Science+Business Media New York (outside the USA) 2014

\begin{abstract}
HIV self-testing (HIVST) is an emerging HIV testing strategy intended to address challenges of increasing access to preliminary knowledge of serostatus. It offers the potential for tests and testing to reach more people than previously possible, including those who do not seek testing in facilities. With approval of an HIV self-test kit in the USA, increasing evidence from public pilot programs in sub-Saharan Africa showing high acceptability and feasibility, and evidence of the informal sale of rapid HIV test kits in the private sector, options for individuals to access HIV self-testing, as well as consumer-demand, appear to be increasing. More recently WHO and UNAIDS have explored self-testing as an option to achieving greater HIV testing coverage to support global treatment targets. However, for resource-limited settings, technological
\end{abstract}

V. Wong $(\square) \cdot$ C. Brown

Office of HIV/AIDS, USAID, Washington, DC 20004, USA

e-mail: vwong@usaid.gov

C. Johnson

HIV Department, WHO, Geneva, Switzerland

E. Cowan

Partners in Diagnostics, LLC, Rockville, MD, USA

M. Rosenthal

USAID Namibia, Windhoek, Namibia

R. Peeling

Department of Clinical Research, London School of Hygiene and Tropical Medicine, London, UK

M. Miralles

Office of Health Systems, USAID, Washington, DC, USA

A. Sands

Department of Essential Medicines and Health Products, World Health Organization, Geneva, Switzerland development, diagnostic device regulation and quality assurance policies are lagging behind. This commentary will examine regulatory and policy issues with HIVST, given its increased prominence as a potential part of the global HIV/AIDS response.

Keywords HIV · Testing - Self testing - VCT · Policy · Regulation · Diagnostics · Rapid test · HTC

\section{HIV Self-Testing: Policy Context and Use}

Increasing access to HIV testing and counselling (HTC) remains a priority for global HIV programming, critical for meeting prevention and treatment targets [1-3]. Through a combination of facility- and community-based approaches, an estimated 118 million people tested for HIV across 124 low- and middle-income countries in 2012 [4]. Still, fewer than half of people living with HIV (PLHIV) in Africa are aware of their status; with two million new infections yearly, many remain undiagnosed and at increased risk for morbidity, mortality and onward transmission [4]. Rapid HIV diagnostic tests (RDTs) are critical tools for increasing access to testing and knowledge of HIV sero-status, which many countries have utilized to scale-up HTC access and uptake. The use of RDTs by individuals who want to test themselves and interpret their results in private, through HIV self-testing (HIVST), is an emerging strategy that offers the potential to reach more people than previously possible, including those who do not present at health or community facilities for HIV testing [5]. While non-HIV self-testing has been introduced successfully for other diseases and conditions [6], HIVST in resource-limited settings presents some unique potential challenges and risks, as well as substantial opportunities for testing expansion. 
Currently most HIV RDTs are intended for use only by trained healthcare providers. Because results provided by these diagnostic devices have both serious individual and public health implications, and potential for harm due to false results (e.g. increased transmission, unnecessary treatment through false or unconfirmed positive results, non-access to treatment), HIV RDTs have been classified as "high risk devices". As such, they must meet minimum performance standards, and diagnoses are made only through validated, multi-test algorithms [2, 7]. Nevertheless, benefits of HIVST within specific settings and populations have now been documented in literature reviews [810], pilot studies [11-13], meeting reports [14], technical updates [15], and interim data and research [16-18].

Governments and policy makers must now play a key role in considering both the potential benefits and harms that may result from HIVST; and where HIVST is adopted, develop systems to monitor and regulate the sale, distribution and use of diagnostics intended for HIVST. The success of HIV self-testing efforts will require maximizing benefits while minimizing harm, and involve regulations stemming from legal systems that establish diagnostic standards and provide authority and context to implement responsible policies; and national health policies which, within the confines of medical device regulation, should guide and inform HIV self-testing implementation in both the public and private sectors (see Table 1).

HIVST policies and HIVST RDT regulation will clearly be informed by the increasing evidence-base. Pilot studies in Malawi and Kenya have demonstrated generally high acceptability among health workers and the general populations [11, 12], along with high accuracy of self-testing with HIV RDTs that use oral fluid, when combined with a demonstration step and illustrated instructions [11, 16, 17]. In the USA, France and Australia, acceptability of targeted HIVST is reportedly high among men who have sex with men [19-21]. There have been only limited studies on unsupervised HIVST in resource-limited settings [8, 12]. One South African study of unsupervised/uninstructed selftesting among health care workers found low sensitivity (66.7\%) [22]. Another South African study reported high accuracy using a fingerstick HIVST kit with tailored instructions for use among rural and urban men and women with minimal education in KwaZuluNatal, where $99 \%$ of participants received a valid result, with a sensitivity of $97.4 \%$ (95 \% CI 86.47-99.57\%) [23]. The positive findings of many of these studies will lead to increasing calls for implementation; as technologies come online, testing regulation and policies will need to be adapted.

At present, self-testing and self-tests mean different things in different countries. Implementation approaches to HIVST and existing policies are diverse. Access to RDTs varies, with some countries having no policies or legal/
Table 1 Definitions: regulatory authority and health policy

Regulatory authority is a government body or other entity that exercises a legal right to control the use or sale of medical devices within its jurisdiction, and that may take enforcement action to ensure that medical products marketed within its jurisdiction comply with legal requirements [7, 49]

Regulatory capacity may be considered a given country's ability to control the quality, safety and efficacy of medicines and medical devices circulating on their markets or passing through their territories [50]

Health policy refers to decisions, plans, and actions that are undertaken to achieve specific health care goals within a society. An explicit health policy can achieve several things: it defines a vision for the future which in turn helps to establish targets and points of reference for the short and medium term. It outlines priorities and the expected roles of different groups; and it builds consensus and informs people [51]

regulatory uncertainty on how policies apply to HIVST, to others with open access to consumers in the private sector, such as the USA (see Table 2) [14]. Increasingly, selftesting is also occurring through the private sector in resource-limited countries, where professional-use RDTs are varyingly packaged and sold directly to consumers [24]. This corresponds with high-utilization of privatesector HIV services for HIV testing and treatment [25, 26]. However, these services are often unregulated and not covered within national HIV policies, and the ability of governments to ensure appropriate, quality RDTs is limited. Despite or because of this absence of regulation, RDT distribution continues through pharmacies, Internet sales, groceries and other businesses [24, 27-29]. With this crosssection of studies, pilot programs and reports of informal self-testing, HIVST implementation, interest and access appear to be expanding. As countries explore the benefits and risks of these multiple approaches to HIVST, due consideration should be given to the availability of quality RDTs and HIVST kits that meet international and national standards for testing in the intended populations in conjunction with any proposals of HIVST policy.

\section{Regulatory and Policy Issues with HIVST: Balancing Risks and Benefits}

HIV self-testing was recently defined by WHO as a process in which individuals being tested conduct the testing process, collect the specimen, run the test, and read and interpret the result [14, 15]. And for medical devices generally, WHO has articulated seven principles for effective regulation [30], all equally relevant for HIV selftesting devices, including: protection of public heath and safety; assurance to access to valuable new technologies; science-based regulatory decision-making; effective rule of 
Table 2 Selected country policies on HIV self-testing

\begin{tabular}{|c|c|c|}
\hline Country & $\begin{array}{l}\text { HIV self-testing policy, } \\
\text { guidance or law }\end{array}$ & Access restrictions \\
\hline Australia [52] & Currently not legal & $\begin{array}{l}\text { Explicitly restricted use } \\
\text { to only health } \\
\text { professionals }\end{array}$ \\
\hline Botswana & $\begin{array}{l}\text { Currently not legal- } \\
\text { stated in Sept } 2013 \\
\text { policy }\end{array}$ & $\begin{array}{l}\text { Public Health Bill } 2013 \\
\text { restricts use to health } \\
\text { professionals }\end{array}$ \\
\hline Kenya [43] & $\begin{array}{l}\text { Legal since 2008; } \\
\text { included in National } \\
\text { HTC Policy }\end{array}$ & $\begin{array}{l}\text { Nationally approved } \\
\text { tests only; vendor } \\
\text { training and instruction } \\
\text { are required }\end{array}$ \\
\hline $\begin{array}{l}\text { Hong Kong } \\
\text { [53] }\end{array}$ & Currently legal & $\begin{array}{l}\text { Only the US FDA } \\
\text { approved kit is } \\
\text { approved; the } \\
\text { government provides } \\
\text { information on self- } \\
\text { testing and information } \\
\text { on a general free } \\
\text { hotline }\end{array}$ \\
\hline $\begin{array}{l}\text { Namibia }[24, \\
28]\end{array}$ & $\begin{array}{l}\text { No specific guidelines, } \\
\text { laws or policies, } \\
\text { although RDTs are } \\
\text { regulated as medical } \\
\text { devices. Private sector } \\
\text { appears unregulated }\end{array}$ & $\begin{array}{l}\text { Private sector appears } \\
\text { unregulated }\end{array}$ \\
\hline France [37] & $\begin{array}{l}\text { Legal to purchase } \\
\text { approved HIV self-test } \\
\text { kits planned in } 2014\end{array}$ & $\begin{array}{l}\text { National regulatory } \\
\text { approval of self-test } \\
\text { kits; }\end{array}$ \\
\hline $\begin{array}{l}\text { United } \\
\text { Kingdom } \\
{[36]}\end{array}$ & $\begin{array}{l}\text { Legal to purchase } \\
\text { approved HIV self-test } \\
\text { kits }\end{array}$ & $\begin{array}{l}\text { National regulatory } \\
\text { approval of self-test } \\
\text { kits; not available } \\
\text { HIVST kits in the } \\
\text { market }\end{array}$ \\
\hline $\begin{array}{l}\text { United States } \\
{[32,35]}\end{array}$ & $\begin{array}{l}\text { Legal to purchase } \\
\text { approved HIV self-test } \\
\text { kits since July } 2012\end{array}$ & $\begin{array}{l}\text { National regulatory } \\
\text { approval of self-test } \\
\text { kits; Currently } \\
\text { approved kit is for age } \\
17 \text { and over }\end{array}$ \\
\hline $\begin{array}{l}\text { South Africa } \\
\text { [27] }\end{array}$ & $\begin{array}{l}\text { Currently legal for } \\
\text { HIVST kits to be } \\
\text { accessed through some } \\
\text { stores and the internet } \\
\text { but not in pharmacies }\end{array}$ & $\begin{array}{l}\text { No clear regulatory } \\
\text { policies on the quality } \\
\text { of available HIVST } \\
\text { kits }\end{array}$ \\
\hline $\begin{array}{l}\text { Multilateral- } \\
\text { WHO [21, } \\
54]\end{array}$ & $\begin{array}{l}\text { Currently no normative } \\
\text { guidelines and no } \\
\text { RDTs intended for } \\
\text { self-testing have been } \\
\text { pre-qualified }\end{array}$ & \\
\hline
\end{tabular}

law; government prescribed rules; assurance of device safety; and communication of information on risks. Country contexts, including its prevalence, will influence governments' determinations about enacting effective regulation of HIVST devices. Australia and the US provide two contrasting regulatory examples. In Australia, a country with a sophisticated regulatory environment, HIV self-testing is not currently legally supported as any HIV testing requires "appropriate level of interaction (with) a suitably qualified health professional" [31]. By contrast, an HIVST kit was made available in the United States in 2012 with the U.S. Food and Drug Administration (FDA)'s approval of the OraQuick ${ }^{\circledR}$ In-Home HIV Test $[32,33]$. This was the first complete, over-the-counter diagnostic test system for an infectious disease approved in the USA for consumer-use [34, 35]. A key aspect of the approval process was a risk-benefit model, finding that 4,000 new infections could be averted and 44,000 people would learn their HIV status in the first year of introduction [32, 33]. A similar approach was implemented in 2014 in the United Kingdom and is planned for France [36, 37].

The FDA approval has generated interest globally in making similar devices available in resource-limited settings. However, this approval was based on a test specifically designed for consumer-use in a U.S. market, with its design and performance validation based on U.S. population studies. Thus, the safety and effectiveness of this RDT in populations outside the US needs to be determined, and risk-benefit profiles would likely differ in resource-limited settings and those with higher HIV prevalence rates. Moreover, regulatory systems for diagnostics in many African countries tend to be weak and not every country has a regulatory body overseeing medical devices [38-41]. A 2002 WHO survey found that 42 out of 86 resource-limited countries surveyed reported having medical device regulations, and 11 out of 15 African countries had no regulatory structure for diagnostic devices [42]. Still, millions of rapid HIV tests are conducted through the public health sector annually within existing national policy frameworks, often supported by quality mechanisms such as WHO diagnostic pre-qualification and Ministry of Health validation of test kits $[2,4]$. For countries considering the approach, HIVST will benefit from clear regulations and policies that ensure appropriate test kits are brought to market and quality will be ensured. And although HIVST regulatory efforts and policies in most resource-constrained countries are nascent, country activities around HIVST is evident:

- In Kenya, responding to demand and informal use of HIV RDTs for self-testing among healthcare workers and increasing availability of oral fluid RDTs, the 2008 National HTC guidelines incorporated a policy specific to HIV self-testing [43]. Criteria for approval of RDTs for self-testing include: (1) evaluation and approval of the test in Kenya; (2) storage and quality control standards; (3) pharmacist training and approval to dispense, counsel, and demonstrate use to clients; and (4) making accessible follow-up and referral services, including services for confirming positive test results. Despite inclusion of HIVST in policy for the general 
population, implementation in the pubic sector has been limited.

- In South Africa, national policies permit HIV RDTs to be sold over the internet and in some stores, but not in pharmacies, and effective regulation of RDTs is difficult [27]. Concerns exist regarding informal HIVST and questions around the accuracy, interpretability, usability, and quality of available HIV RDTs designed for professionals but sold to consumers for HIV selftesting. Such limitations have solicited response and advocacy from the South African HIV Clinician's Society, which in 2012 requested that policy limiting the sale of HIV RDTs over-the-counter be amended [44]. South Africa is currently reviewing their existing policies and may develop additional policies and regulations to support sale in pharmacies.

- In Namibia, there is evidence of demand and sale of clinical-use HIV RDTs in private sector pharmacies at low levels relative to overall numbers tested, nevertheless, sales volumes may be expanding; two distributors reported increased RDT volumes sold between 2011 and 2012 (45 and $72 \%$ increases, respectively) [5]. While HIV self-testing is not addressed in the National HIV Strategic Framework, there are legal frameworks that regulate diagnostic devices. However, these are not currently applied to the private sector. Currently the Government of Namibia is working to develop specific policies addressing HIVST.

\section{Future Directions: HIV Rapid Diagnostics and Self- Testing}

The WHO has emphasized that "the use of rapid tests for HIVST requires a regulatory framework that ensures quality diagnostics that give accurate results in the hands of the intended user(s)" and that while HIVST shows much promise, regulations and policies still require adaptation [5, 14]. Regulatory processes will need updating for new technologies and expansions of intended-use. Strengthening regulatory infrastructures and assisting with policy development and decision-making related to the evaluation, sale or introduction of HIV rapid diagnostic tests intended for use by consumers should be a priority [42].

The US FDA provides one example for regulation of self-testing technology, where diagnostics are legally regulated in both public and private sectors. While the medical device regulatory infrastructures of many resource-limited countries remains weak, effective regulatory frameworks may yet be established to guide policy development related to the use HIV RDTs for self-testing and contribute to an environment where appropriate testing platforms intended for consumer use are made available [42]. Given the high acceptability, increasing global interest, and potential public health benefit in expanding HIVST, there are specific regulatory and policy domains that should be addressed globally and at the country level:

\section{Regulatory Oversight}

To support the quality of HIVST and associated RDTs countries should, based on WHO frameworks, consider supporting the following elements [45]:

- Ensure that all importation, exportation, wholesale and distribution establishments for RDTs are licensed

- Before HIVST RDTs are marketed or programmed, consider and assess their quality, safety and efficacy for their intended-use

- Monitor the quality and safety of diagnostics on the market to prevent harmful, substandard and counterfeit devices from reaching the public

- Monitor advertising and promotion of these devices, and provide independent information on their rational use to the public and professionals

- Post-marketing surveillance to monitor the ongoing quality of tests sold, and laws that prevent low quality tests from entering the market

- Develop policies and systems for corrective action

For countries with limited capacity to control the quality, safety and efficacy of HIVST, assessments of the medical device regulatory systems may identify gaps and needed frameworks to regulate the use and sale of HIVST in the public and private sectors. Countries should work towards consistent implementation of essential regulatory functions, based on the key provisions of the existing legal frameworks, addressing regulatory system strengthening needed to support HIVST. Efforts at strengthening management structures, technical regulatory expertise and physical resources may be needed, in addition to monitoring mechanisms of OTC sale of test kits. There is also a role for regional regulatory-strengthening initiatives that support regulation of diagnostics, and international and donor quality assurance processes that inform procurement decisions in evaluating self-testing RDTs [46-48].

\section{Diagnostic Technology Assessment and Policy Development}

National disease control programs should assess RDTs for self-testing as intended for implementation (e.g. through supervised self-testing, or open access) and consider their strategic placement to maximize the health-impacts and minimize risks. HIVST policy development will depend on considerations that include effectiveness, and since HIV self-test kits may have different performance characteristics 
in different populations, validation of RDTs may be needed for diverse groups of "intended users" within countries, regions and even settings, and both public and private sectors should be considered. Risk-benefit modeling may be an important component of an evaluation, informing what test performance is acceptable. Policies should clarify where and by whom an HIV test can be performed or interpreted, requirements for face-to-face counseling, and how HIVST relates to national algorithms. Developing national models to estimate these parameters are important priorities. Additionally, considerations will include determining whether the HIV self-tests are made formally available through the private sector or restricted to HIV programs with integrated counselling and self-test training/ instruction.

\section{Implementation}

Building on a national policy/regulatory framework developed establishing HIVST, implementation will involve the development of training modules for the public and private sectors, establishment of quality assurance systems, monitoring and evaluation (including of adverse outcomes), and support for linkage to additional testing, care and treatment. Additional implementation issues include:

- Building an evidence-base on optimal operational approaches and use to include feasibility studies and impact evaluations to inform approaches that maximize benefit and minimize harm [55]

- Increased numbers of preliminary reactive self-test results may increase demand for HTC and care/ treatment; health systems must accommodate increased utilization

- Ethical issues that accompany HIV self-testing require attention, including coercive testing

- The role of public/private partnerships in sustainable approaches to HIV programs should be clarified

- Opportunity to leverage expertise and experience of other countries in the region on these and related issues

- Potential replacement of HTC with HIVST could lead to increased prevalence in certain populations and settings, from false-negative results [56]

\section{Industry Engagement}

Efforts are needed to engage the HIV diagnostics industry and other stakeholders to establish optimal target product profiles and minimum performance characteristics for RDTs intended for self-testing use in resource-limited countries. Harmonizing "minimum standards" of self-test devices for diverse populations will be critical, as well as engaging with manufacturers in optimizing HIV self-test kit design to meet these minimum performance standards for intended populations.

\section{Conclusion}

HIVST offers the opportunity to expand HIV testing, allowing individuals to test themselves and providing preliminary knowledge of HIV sero-status. HIV RDTs are considered "high-risk" diagnostic devices and results obtained by intended users can have significant implications for an individual's health and HIV transmission. Broadly, it's recognized that increased access to testing can contribute to attaining public health goals, and HIV selftesting is an innovative strategy to expanding access. Pilot studies globally have documented high HIVST acceptability. Additionally, there is demonstrated demand for access to RDTs for self-testing in the private sector. If HIVST is to expand, regulatory frameworks supporting appropriate HIVST devices and self-testing implementation policies are both needed, and equally important. Device regulation and clear policies should precede implementation. As countries consider the risks, benefits, feasibility and acceptability of introducing HIVST, ensuring appropriate, safe, and effective diagnostics that meet defined standards in the hands of intended users should ensure maximal benefit and minimal risk to public and individual health. For self-testing devices, the regulatory processes needed to achieve these aims may leverage existing systems regulating devices and/or require further systems, development, and investment. Policies guiding HIVST implementation should be harmonized with diagnostic device regulation. Evidence and experience around non-HIV home diagnostics that have proven effective (while for conditions and diseases more benign than HIV) may help inform approaches to policies, regulation, research and evaluation. Short-term strategies that include broad stakeholder engagement to ensure appropriate and quality tests, and quality assurance processes that support HIVST should be complemented with country readiness assessments around the conditions of their possible introduction. Longer-term strategies for strengthening country regulatory capacity for HIV diagnostics, including self-test RDTs continue to be needed. While questions remain regarding the programmatic implementation of HIV selftesting and its impacts, the approach has a great potentialwith safeguards in place-to significantly increase access to HIV testing, and support global goals around HIV treatment, care and prevention.

Acknowledgments We thank Brad Corner (USAID, Namibia), Elisabeth Ludeman (USAID, Washington DC, Office of Health Systems) and Cheryl Dietrich (USAID, Washington DC, Office of HIV/ AIDS) for their reviews and contributions to this article. 


\section{References}

1. U.S. Department of State. PEPFAR blueprint: creating and AIDSfree generation. Washington DC, 2012.

2. WHO. Service delivery approaches to HIV testing and counseling (HTC): a strategic HTC programme framework. Geneva, 2012.

3. WHO. Handbook for improving HIV testing and counseling services. Geneva. 2011.

4. WHO. Global update on HIV treatment 2013: results, impact and opportunities. Geneva, 2013.

5. WHO. Supplement to the 2013 consolidated guidelines on the use of antiretroviral drugs for treating and preventing HIV infection: recommendations for a public health approach. 2014.

6. Ibitoye M, Frasca T, Giguere R, Carballo-Diéguez A. Home testing past, present and future: lessons learned and implications for HIV home tests. AIDS Behav. 2014;18(5):933-49.

7. Global Harmonization Task Force. Principles of in vitro diagnostic (IVD) medical devices classification. Available from http://www.imdrf.org/docs/ghtf/archived/sg1/technical-docs/ghtfsg1-n045r12-invitro-diagnostic-classification-070209.pdf (2007). Accessed 18 April 2014.

8. Pant Pai N, Sharma J, Shivkumar S, et al. Supervised and unsupervised self-testing for HIV in high- and low-risk populations: a systematic review. PLoS Med. 2013;10(4):e1001414.

9. Napierala-Mavedzenge S, Baggeley R, Lo R, Corbett EL. HIV self-testing among health workers: a review of the literature and discussion of current practices, issues and options for increasing access to HIV testing in sub-Saharan Africa, 2011.

10. Krause K, Subklew-Sehume F, Kenyon C, Colebunders R. Acceptability of HIV self-testing: a systematic literature review. BMC Public Health. 2013;13:735.

11. Choko A, Desmond N, Webb EL, Chavula K, Napierala-Mavedzenge S, Gaydos CA, Makombe SD, Chunda T, Squire SB, French N, Mwapasa V, Corbett EL. The uptake and accuracy of oral kits for HIV self-testing in high HIV prevalence setting: a cross-sectional feasibility study in Blantyre, Malawi. PLoS Med. 2011;8(10):e1001102.

12. Kalibala S, Tun W, Muraah W, et al. 'Knowing myself first': feasibility of self-testing among health workers in Kenya. Nairobi: Population Council; 2011.

13. el Fuente L, Rosales-Statkus ME, Hoyos J, et al. Are participants in a street-based HIV testing program able to perform their own rapid test and interpret the results? PLoS ONE. 2012;7(10):e46555.

14. WHO. Report on the first international symposium on self-testing for HIV: the legal, ethical, gender, human rights and public health implications of self-testing scale-up. Geneva, 2013. http://who. int/hiv/pub/vct/self_test/en/index.html.

15. WHO. 2014. Draft Technical update: self-testing for HIV (forthcoming).

16. MacPherson P, Lalloo D, Choko A, van Oosterhaut J, Thindwa D, Webb E, Squire B, Makombe S, Hayes R, Corbett E. Home assessment and initiation of ART following HIV self-testing: a cluster randomised trial to improve linkage to ART in Blantyre, Malawi. 20th Conference of Retroviruses and Opportunistic Infections (CROI). Oral LB95. 2013 Mar 3-6. Atlanta, Georgia.

17. Corbett E. Accuracy of self-testing and linkage to care and treatment. Presented at: first international symposium on selftesting for HIV, 8-9 April 2013, Brocher Foundation, Geneva, Switzerland.

18. Kumwenda M. Partnership dynamics and care-seeking trajectories among couples after HIV self-testing in Blantyre. Presented at: first international symposium on self-testing for HIV, 8-9 April 2013, Brocher Foundation, Geneva, Switzerland.

19. Carballo-Diéguez A, Frasca T, Balan I, Ibitoye M, Dolezal C. Use of a rapid HIV home test prevents HIV exposure in a high risk sample of men who have sex with men. AIDS Behav. 2012;16(7):1753-60.

20. Bavinton BR, Brown G, Hurley M, Bradley J, Keen P, Conway DP, Guy R, Grulich AE, Prestage G. Which gay men would increase their frequency of HIV testing with home self-testing? AIDS Behav. 2013;17(6):2084-92.

21. Greacen T, Friboulet D, Blachier A, Fugon L, Hefez S, Lorente $\mathrm{N}$, Spire B. Internet-using men who have sex with men would be interested in accessing authorised HIV self-tests available for purchase online. AIDS Care. 2013;25(1):49-54.

22. Pant Pai N, Behlim T, Abrahams L, Vadnais C, Shivkumar S, et al. Will an unsupervised self-testing strategy for HIV work in health care workers of South Africa? a cross sectional pilot feasibility study. PLoS ONE. 2013;8(11):e79772.

23. Dong M, Regina R, Hlongwane S, Ghebremichael M, Wilson D, Dong K. Can laypersons in high-prevalence South Africa perform an HIV self-test accurately? 20th International AIDS Conference, 2014 July 20-25, Melbourne, Australia. Abstract No. A-641-0087-10374.

24. Nersesian P, Hülsmann M, Cloutier S, and Chintalova-Dallas R. Assessment of over-the-Counter HIV rapid test kits in Namibia. Arlington, VA. USAID AIDS Support and Technical Assistance Resources, AIDSTAR-One, Task Order 1. 2013. Available from: http://www.aidstar-one.com/sites/default/files/AIDSTAR-One_ Report_Namibia_OTC_Rapid_Test_Kits.pdf.

25. Strengthening Health Outcomes through the Private Sector. HIV testing by private health providers: evidence from 18 countries. Washington DC. Available from: http://www.shopsproject.org/ resource-center/hiv-testing-by-private-health-providers-evidencefrom-18-countries (2012). Accessed 4 Nov 2013.

26. Sargent J, Johnson, J, Majorowski, M, Friedman, N, and Blazer, C. Private sector involvement in HIV service provision. Arlington, VA: USAID AIDS Support and Technical Assistance Resources, AIDSTAR-One Project, Task Order 1. Available from: http:// www.aidstar-one.com/sites/default/files/AIDSTAR-One Private Sector_Tech_Brief_rev.pdf (2009). Accessed 4 Nov 2013.

27. Richter M, Venter FD, Gray A. Home self-testing for HIV: AIDS exceptionalism gone wrong. South African Medical Journal. 2010;100(10).

28. Muraranganda E. Govt probes HIV self-test kits. Namibian Sun. Available from: http://www.namibiansun.com/health/govtprobes-hiv-self-test-kits.54388 (2013). Accessed 26 June 2013.

29. Anonymous. Home-testing kits for HIV now available amid concern. The Star. Available from: http://www.hst.org.za/news/ home-testing-kits-hiv-now-available-amid-concern

(2000). Accessed 4 Nov 2013.

30. WHO, Pan-American Health Organization. A model regulatory program for medical devices: an international guide. Geneva, 2001. Available from: http://www1.paho.org/English/HSP/HSE/ medical_devices.pdf. Accessed Nov 4, 2013.

31. Australasian Society for HIV Medicine. 2012 National HIV testing policy v1.2. Surry Hills, Australia. 2012. http://test ingportal.ashm.org.au/hiv/home-based-testing-in-australia.

32. United States Food and Drug Administration. OraQuick ${ }^{\circledR}$ Inhome hiv test summary of safety and effectiveness. Washington DC. 2012. Available from: http://www.fda.gov/downloads/Biolo gicsBloodVaccines/BloodBloodProducts/ApprovedProducts/Pre marketApprovalsPMAs/UCM312534.pdf. Accessed Nov 4, 2013.

33. Oraquick Technologies. Final advisory committee briefing materials: OraQuick ${ }^{\circledR}$ In-Home HIV test. Available from: http:// www.fda.gov/downloads/AdvisoryCommittees/CommitteesMee tingMaterials/BloodVaccinesandOtherBiologics/BloodProducts AdvisoryCommittee/UCM303652.pdf (2012). Accessed 4 Nov 2013.

34. CDC. HIV surveillance-United States, 1981-2008. Morb Mortal Weekly Rep. 2011;60(21):689-693. 
35. US FDA. First rapid home-use HIV kit approved for self-testing. Available from: http://www.fda.gov/forconsumers/consumerup dates/ucm310545.htm (2013). Accessed 4 Nov 2013.

36. Department of Public Health. Modernisation of HIV rules to better protect public. London. Available from: https://www.gov. uk/government/news/modernisation-of-hiv-rules-to-better-protectpublic (2013). Accessed 4 Nov 2013.

37. NY Daily News. France OKs home tests for HIV. Available from: http://www.nydailynews.com/life-style/health/france-okshome-tests-hiv-article-1.1510008 (2013). Accessed 31 Jan 2014.

38. WHO. Medical device regulation-global overview and guiding principles. Geneva, 2003.

39. Peeling R. Update on regulatory harmonization of in vitro diagnostics in Africa. Presented at: Global HIV Diagnostics Working Group Meeting. Sep 2013, Geneva, Switzerland.

40. Preston C, Valdez ML, Bond K. Strengthening medical product regulation in low and middle income countries. PloS Med. 2012;9(10):e1001327.

41. WHO. National regulatory agency for medical devices (map). Available from: http://gamapserver.who.int/mapLibrary/Files/ Maps/Global_DIM_Indicator3_20110211.PNG (2011). Accessed 4 Nov 2013.

42. WHO. Increasing access to diagnostics through technology transfer and local production. Geneva, 2011.

43. National AIDS and STD Control Programme. National guidelines for HIV testing and counseling in Kenya. Nairobi. Available from: http://www.ilo.org/wcmsp5/groups/public/—ed_protect/protrav/_ilo_aids/documents/legaldocument/wcms_127533.pdf (2008). Accessed 31 Oct 2013.

44. South African HIV Clinicians Society, Treatment Action Campaign. Joint statement on HIV testing and counselling, Johannesburg. Available from: http://www.sahivsoc.org/newsroom/ society-news (2012). Accessed 31 Oct 2013.

45. WHO. Effective medicines regulation: ensuring safety, efficacy and quality. Policy Perspectives on Medicines No. 7. Available from: http://whqlibdoc.who.int/hq/2003/WHO_EDM_2003.2.pdf (2003). Accessed 4 Nov 2013.

46. Pan African Harmonization Working Party on Medical Devices and Diagnostics. Available from: http://pahwp.org/index.html (2014). Accessed 18 April 2018.
47. WHO. WHO Prequalification of Diagnostics Programme. Available from: http://www.who.int/diagnostics_laboratory/eva luations/en/ (2014). Accessed 18 April 2014

48. USAID. HIV rapid test kits approval and technical guidance. Available from: http://www.usaid.gov/sites/default/files/docu ments/1864/GuidanceHIVRTKs.pdf (2013). Accessed 18 April 2014.

49. Study Group 1, Global Harmonization Task Force. Principles of conformity assessment for medical devices. Available from: http://www.imdrf.org/docs/ghtf/final/sg1/technical-docs/ghtf-sg1n78-2012-conformity-assessment-medical-devices-121102.pdf (2012). Accessed 31 Jan 2014.

50. WHO. Assessment of medicines regulatory systems in sub-Saharan African countries. Available from: http://www.who.int/ healthsystems/Assessment26African_countries.pdf (2010). Accessed 14 April 2014.

51. WHO. Health Policy. Available from: http://www.who.int/topics/ health_policy/en/ (2013). Accessed 14 April 2014.

52. Australian Government Department of Health and Aging. National HIV testing policy: home based testing in Australia. Available from: http://testingportal.ashm.org.au/hiv/home-basedtesting-in-australia (2012). Accessed 18 April 2014.

53. Hong Kong Department of Health. Knowing about HIV Antibody Test. Available from: http://www.info.gov.hk/aids/english/hot line/testing_question.htm\#d2 (2013). Accessed 31 Jan 2014.

54. WHO, UNAIDS, UNICEF. Global HIV response epidemic: update and health sector progress towards Universal Access, Progress Report. Geneva, 2011.

55. Napierala-Mavedzenge S, Baggaley R, Corbett EL. A review of self-testing for HIV: research and policy priorities in a new era of HIV prevention. Clin Infect Dis. 2013;57(1):126-38.

56. Katz D, Cassels S, Stekler J. Replacing clinic-based tests with home-use tests may increase HIV prevalence among Seattle men who have sex with men: evidence from a mathematical model. Sex Transm Dis. 2014;41(1):2-9. 